\title{
Communities of Song: Collective Musical Participation and Group Singing Experiences In Victoria, BC
}

\author{
SHARONNE K. SPECKER * \\ University of Victoria \\ s.k.specker@gmail.com
}

\begin{abstract}
This research investigates the social processes and effects of participation in two community-oriented choirs in Victoria, BC, and seeks to identify the way in which social cohesion is experienced during group singing practices. Interviews with ten choristers and two conductors reveal the feelings of community that can arise among participants and provide data for exploring how this phenomenon occurs. Results indicate that social bonding in the choral setting manifests itself in various ways. The key factors of a common goal, shared values, a safe environment, community interaction, and social infrastructure facilitate feelings of collective participation, lead to increased levels of trust, equality, connection, and mutual caring. Participant exceptions also emerge, evidence of the group's heterogeneous approach to sociality. Analysis of both the processes and outcomes indicates that this example of social interconnection is consistent with Victor Turner's anthropological definition of communitas, or intense communal bonding.
\end{abstract}

Keywords: community; sociality; singing; choirs; participation

\footnotetext{
"Thanks are extended to the author's supervisor, Dr. Alexandrine BoudreaultFournier; to Dr. Ann Stahl, Anthropology Department Chair; to Dr. Quentin Mackie; to the University of Victoria for the Jamie Cassels Undergraduate Research Award, which facilitated this research; and to the participants of this study, for the generous sharing of their time, thoughts, and music.
} 


\section{INTRODUCTION}

T IfE CAN, at times, provide instances for the individual to join in with the social collective. Singing communally is one such opportunity that has great potential for generating feelings of social cohesion. The knowledge that group singing can foster is widely affirmed in literature both recent and established, but the matter is often approached with a focus on product rather than on process. The present study seeks to uncover how this social experience occurs, how it can be analyzed anthropologically, and how this awareness can be beneficial.

Concerns over increased social isolation and alienation are a recurring point of discussion in the modern world. From the alienationfocused commentary of Marx (1927/1974), to mid-twentieth-century and contemporary debates about the problems of loneliness and social isolation (Cattan, Newell, Bond, and White, 2003; Hortulanus, Machielse, and Meeuwesen, 2006; Josephson and Josephson, 1962; Murchland, 1971; Pappenheim, 2000), trepidation over reduced connection and interaction among citizens of industrial societies has pervaded the social sciences. Hortulanus et al. (2006, p. 4) note that "( $\mathrm{t}$ )he fairly small communities in which people used to live have made way for a multiplicity of social bonds within which people have to function". In this light, activities facilitating communal bonding in contemporary urban society take on a high degree of relevance. I propose that research into the practice of choral singing, through direct interaction with participants themselves, may provide insight into ways in which such social connection is experienced.

Through the study of two Victoria community choirs, the Gettin' Higher Choir and the Victoria Good News Choir, I examine the way in which participants experience collective bonding through practice. Drawing on the work of Victor Turner $(1969,1986)$ and Alfred Schütz (1951), I suggest that singing together can establish a strong sense of social unity, which can be explored through the experiences of "mutual-tuning in" and communitas. This experience of communitas fills an important space in social life - one of interaction, cohesion, 
and validation as part of a group.

The goal of the study is tri-fold: first, it is to gather participant data documenting the lived experiences of shared community in a choir setting, with an emphasis on how these experiences come about. Second, it is to determine whether this experience and context is consistent with the potent feeling of social togetherness referred to as communitas by anthropologist Victor Turner in his seminal studies on ritual and liminality, thus giving further insight into the social processes. Third, it is to open the door to further discussions on how this kind of socio-musical experience can be an effective, positive tool of social intervention and change.

\section{REVIEW}

Extensive research has been done on the topic of group singing, although the interdisciplinary nature of the topic means that the vast majority comes from diverse, non-anthropological sources. The beneficial social components of group singing activities have been significantly addressed in the fields of biology, psychology, health, music therapy, sociology, social work, and music education, as well as in the areas of sound studies and anthropology. The positive impact of the social singing experience has therefore been repeatedly studied and acknowledged, providing a firm and thorough grounding for the present study.

Biological research has asserted the physiological basis of feelings of community derived from group singing experiences. Singing together has been shown to generate release of the so-called "bonding hormone", oxytocin, which may contribute to consequent experiences of communal bonding (Grape, Sandgren, Hansson, Ericson, \& Theorell, 2002). Neurological studies have shown evidence of brainwave synchronization during concurrent musical activity (Lindenberger, Li, Gruber, \& Müller, 2009), and research has revealed that coordinated singing raises and lowers participants' heart rates simultaneously (Vickhoff et al., 2013). Endorphin production accompanies singing, leading to positive shared experiences that can have a unify- 
ing effect (Dunbar, Kaskatis, MacDonald, \& Barra, 2012).

Given these documented factors, it is unsurprising that the field of music therapy has taken particular interest in the shared singing phenomenon. Choral activity has been studied as a means of providing social and psychological benefits to marginalized populations such as homeless men (Bailey \& Davidson, 2002, 2003, 2005) and female prison inmates (Silber, 2005). Bailey and Davidson found that participating in a choir strengthened feelings of community among choir members who had experienced alienation and dissociation through homelessness. Silber's work in a prison in Israel indicated that participation in a choir - involving collaboration, cooperation, focus, and balance - had substantial effects on interpersonal interactions, conflict resolution, and processes of bonding.

Choral singing has also been shown to be beneficial to participants suffering from physical disadvantages such as illness and disability. A study with neurological patients in New Zealand illustrated similar experiences of increased social interaction and feelings of acceptance and community (Fogg and Talmage, 2011). These effects have been extended to more general health studies, which extoll the virtues of participating in choirs for general wellbeing (Eades \& O'Connor, 2008, Gick, 2011). Several studies have examined the effect of creative activities on aging populations, and choral singing in particular has provided an avenue for reducing social isolation and depression (Cohen, 2006; Cohen et al., 2006; Creech, Hallam, Hilary, \& Varvarigou, 2013; Dingle, Brander, Ballantyne, \& Baker, 2012; Greaves \& Farbus, 2006; Teater \& Baldwin, 2014).

In recent years, the focus of studies has begun to include choral singing among the general public. Bailey and Davidson (2005) compared their study of the men's homeless choir with a socioeconomically middle class choir, to research the issues of primary importance for each group. In Australia, Judd and Pooley (2014) studied the role of community choirs for their non-marginalized members. Similar themes emerged, with social cohesion and community engagement ranking high on the list of choral attributes described by participants. This suggests that choral singing has integral unifying features that 
generate feelings of community among participants of all spheres.

Research by Mary Copeland Kennedy (2009) in Victoria, British Columbia sets a precedent for the current study. From a music educator's perspective, she sought to reveal participant experiences of the community-oriented Gettin' Higher Choir (one of the choirs also featured in the present study). Conducted by Shivon Robinsong and Denis Donnelly, and now in its 18th year, the choir's philosophy maintains that anyone can sing and all are welcome. In her fieldwork, Kennedy found that the social aspect of singing in the choir was a very powerful component of members' involvement. She notes that "(b)y far the most important feature of choir membership was the aspect of community established among choir members" (Kennedy 2009:189). However, since the article takes a broad approach to the nature of the choir as a whole, these particular responses are not the focal point and there is limited capacity to explore this topic in detail. Rather, it remains confined to a paragraph. I wished to know more about these social experiences - not merely the fact that they were happening, but how and why they came about, and whether they had elements in common with a more widely applicable experience of social bonding. The localized nature of Kennedy's research meant that I was able to continue with the same choir and region. This study therefore takes these results as the basis for further research and examination, returning to this same choir but seeking to dig deeper into the process to determine the key factors contributing to social cohesion.

In order to examine this social phenomenon in a methodical manner, I sought a system of analysis that could be transferred across genres and be compared to other social practices and activities. An understanding of the social processes inherent in choral participation, and identification of the progression and contextual setting through which these processes occur, equips both the individual and the community with the knowledge needed to use this social and musical resource to its greatest potential.

Coming from the field of anthropology, I chose to situate the topic within an anthropological framework and turned to the work 
of renowned cultural anthropologist Victor Turner. While his ideas about cultural practices and sociality were first posited in the midtwentieth century, and have since been debated and critiqued up until the present day (e.g. Eade \& Sallnow 1991) aspects of his work are still respected as being highly relevant and valid. Turner's writings drew on van Gennep's (1909) outline of the human ritual process, as divided into three basic stages: separation, liminality, and reintegration. Liminality - the most relevant of these categories, for the present study - refers to a transient state of being in limbo, of being in between stages of existence and removed from one's usual structured position in life. It is this state, when shared with others, which can give rise to the compelling feeling of social unity that Turner defines as communitas, and which I will subsequently discuss in relation to the choral experience.

In utilizing Turner's ideas, I have been selective about which aspects I incorporate, and which I reject. Turner's fieldwork in kinshipbased societies emphasizes a division between secularity and sacred ritual, a distinction which I find does not necessarily apply in the case of community choirs. He also suggests that the state of liminality (and consequently communitas) can only occur when a group undergoes a distinct separation from society; again, this is not applicable in my research. However, his discussion of the social relations that facilitate communitas, as well as of the surrounding criteria that may be present, holds a high degree of relevance when analysing similar experiences among choral members.

Turner describes communitas as a sensation of intense social bonding, occurring spontaneously when a group of individuals undergo the same shared, equalizing experience (Turner, 1969:96-97). Drawing on ritual examples, Turner suggests that communitas occurs when participants join together in a procedure or activity that generates a context of

lowliness and sacredness, of homogeneity and comradeship. We are presented, in such rites, with a "moment in and out of time," and in and out of secular social structure, which reveals, however fleetingly, some recognition (in 
symbol if not always in language) of a generalized social bond that has ceased to be and has simultaneously yet to be fragmented into a multiplicity of structural ties. These are the ties organized in terms either of caste, class, or rank hierarchies or of segmentary oppositions...

(Turner 1969:96; my emphasis)

Turner posits that the circumstances necessary to experience communitas are those that accompany a liminal state - a situation of being "in-between" or removed from normative social states or conditions.

Turner compares two possible circumstances of social existence - one of structure, and one of anti-structure. The first involves being firmly situated in one's hierarchical social role or position. The second, characterized in liminality, involves the opposite traits. These include equality, anonymity, absence of status and rank, heteronomy, and humility (1969, p. 106). He explains that the latter state of this dialectic, and the consistent inverse relationship between them both, is "a matter of giving recognition to an essential and generic human bond, without which there could be no society" (1969, p. 97). According to Turner, the experience of communitas occurring in liminality "dissolves the norms that govern structures and institutionalized relationships" (1969, p. 128). The high and the low temporarily come together, acknowledging one another's innate humanness and social validity. In Turner's view, this group of equals is often presided over by an external authority figure (although this suggests inconsistencies pertaining to the hierarchy/equality dialectic). The process of coming together as equals, departed from their usual roles in society, is prevalent in choral participation, leading me to believe that Turner's approach may be justly applied to an analysis of the associated social experience.

While Turner's work forms the primary theoretical foundation for my study, various additional sources supplement and further complement this approach. Edith Turner (2012), in her recent book Communitas: The Anthropology of Collective foy, notes that music, among other activities, can serve as a vessel for the communitas experience of social cohesion. Anthropologist and musicologist Thomas Turino 
(2008) further pursues this principle in the introduction to Music as Social Life: The Politics of Participation. He suggests that joining in musical performance constitutes a transient, exceptional experience akin to the aforementioned state of liminality. He also points out that making sounds collectively requires blending and cooperation, resulting in synchrony (a similar point is made by Silber, 2005). Turino notes that participatory musical practices are usually focused on egalitarian relations and a welcoming community spirit, that they are often "more about the social relations being realized" (2008, p. 29), and can, in any context, be "valuable for processes of personal and social integration" (2008, p. 1). This important community role of shared music-making is represented by the ideologies of the choirs featured in this study, and evidence of the social dimension was expected to be strongly present in the impressions of participants.

Sociologist Alfred Schütz (1951) has argued that shared musical practices have a unique capacity for facilitating interpersonal relationships, through a process in which "each, simultaneously, shares in vivid present the other's stream of consciousness in immediacy" (1951, p. 95) The experience of participating in the same immediate musical moment may provide another example of the way in which communitas is experienced by choral participants. Schütz further elaborates on this concept, stating that:

...this sharing of each other's flux of experiences in inner time, this living through a vivid present in common, constitutes...the mutual tuning-in relationship, the experience of the "We", which is at the foundation of all possible communication.

(Schütz 1951:92)

The "mutual tuning-in relationship" expressed by Schütz in many ways epitomizes the way in which communitas can be applied to choral singing. His allusion to a collective "We" - derived from the "I" and "Thou" - is a probable expression of Buber's "I-Thou" philosophy (1923/1970), which is also referenced by Turner in his discussion of communitas (1969, p. 126-127), linking these respective approaches. 
I propose that communitas can be realized through group singing practices based on the way in which individuals join together in pursuit of common values and goals. In a choral setting, the opposition to societal structure is not intentional so much as circumstantial - to effectively create a successful choral product, one must put aside personal differences in favour of the collective whole. I suggest that this characteristic may emerge in participant responses, and that Turner's approach to social relationships in a liminal context may provide a theoretical basis for the common experience of social bonding through choir membership and group singing, as well as illustrate a means by which the individual may feel themselves to be part of a social collective.

\section{MEthods}

For this project I interviewed a total of ten choir members and two conductors from two different community choirs in Victoria, B.C., Canada. I chose the choirs - the Gettin' Higher Choir and the Victoria Good News Choir - based on their inclusive, community-oriented ideology, and because they were secular, amateur, non-auditioned, mixed-voice, and voluntary. Since the study focused specifically on how singing together can be experienced as a communal social mechanism, it made sense to choose choirs for which social communion was part of the intended goal. It was also preferable to avoid any compounding factors resulting from a religious context, obligatory participation, or professionally oriented musical goals. This will have had an effect on the data collected, as participants were aware of the community focus of the choir and the study; different results would have been obtained had the sample choirs maintained a different ethos.

The Human Research Ethics Board at the University of Victoria provided approval to undertake the project. In this study I sought to take a phenomenological approach, documenting the first-hand experiences of participants in order to best represent the social dynamics of the choir from the ground up. My goal was not simply to provide further definitive evidence that choirs are social, but rather to doc- 
ument how this sociality is experienced. Therefore, in the style of Kennedy (2009) and Judd and Pooley (2014), I concluded that semistructured one-on-one interviews would be the most effective for gathering this type of qualitative data.

Following contact with choir directors, I attended a rehearsal of each choir, explaining the nature of the research and offering an information package with further information, my contact information, and a copy of the consent form. The sample obtained was therefore a sample of convenience, as only interested and forthcoming choir members took the information and subsequently contacted me to agree to participate in the study. I conducted the interviews in a convenient location for participants, and they were audio-recorded. A sample list of key interview questions is included in Table 1. Participants had the option of remaining anonymous. Although the majority agreed to be named, I have represented participants by single letters for the sake of convenience, and altered the letters of those who chose to remain anonymous to protect their identity.

Table 1: Sample interview questions

Why do you sing?

Why do you sing in a choir/group?

What is the social atmosphere like?

How do you feel when you sing in a choir? Physically? Emotionally?

How do people in the choir relate to each other?

How does a choir compare to other group activities?

How does performance compare to rehearsal?

How are choir activities in relation to other activities in your life?

Through what avenues do you experience a sense of community?

I used these questions in most interviews so as to maintain consistency. However, due to the semi-structured nature of the interviews, further unanticipated discussion also emerged during the fieldwork process and informed the collected data. 
Following data collection, I sorted the responses and grouped them into themes, as recommended by Judd and Pooley (2014). Relevant quotes have been included for each section. In keeping with the desire to represent the experience of choristers themselves, the full context of the quotes has sometimes been included in the paper, so as to give a more insightful picture of the individual cases.

\section{Results}

Participant responses were divided into two general categories, (1) responses that specifically involved the sonic experience of singing in a choir; and (2) responses that encompassed the broader social context of the experience. The first of these categories is addressed at length in a separate paper (Specker, 2014, unpublished). It included physical engagement; multi-sensory embodiment; sound production, perception, and harmony; creation; shared sound as social therapy; and sound as collective memory. The second category, examined below, featured more widely applicable social experiences that can be discussed through the framework of Turner's common liminal criteria and identified as examples of communitas. Most cases indicated feelings of community among participants. However, there were also exceptions and instances in which the choirs did not fulfill the expected function.

Social cohesion encompasses a range of experiences. The emergent factors that contributed to social cohesion were (a) working towards a common goal, (b) shared values or topics of interest, (c) an accepting environment, (d) interaction with the greater community, and (e) external/extracurricular social infrastructure. These, in turn, contributed to the secondary outcomes of establishing a common connection, caring about each other as a group, mutual equality and responsibility, and trust. Of the participants, four choir members cited social engagement as a primary reason for joining the choir, while four also joined the choir because of pre-existing social connections. The conductors of the Gettin' Higher Choir also gave input as to the 
social dynamics of the choir 1 $^{\text {t }}$

The conductors in this context play dual, dialectical roles. Turner himself juxtaposes equality with authority in a somewhat conflicting manner, as one of his criteria for liminality refers to an alliance of temporary equals who nonetheless submit to a figure of authority, the latter remaining outside the liminal group. In this respect, the conductors represent the authority figures. Previous research has been carried out on the topic of conductor influence on choral participants (Durrant 2005), and further research could be done in this respect, although this was not my area of focus due to the relatively constrained scope of the study.

However, particularly in the Gettin' Higher Choir, the emphasis on inclusion is such that the conductors also play a participatory role in the experience. One chorister commented on how she perceived the conductors as treating the choir members as equals. One of the conductors also noted the leveling properties of communal vocal participation (see below), and in working towards a final performance both the conductors and choristers were sharing a common goal. Given this dynamic, I felt it was important to interview the conductors as well as the choristers. I also felt that the conductors would be able to draw on prior experiences with choirs, to illuminate their reasons and objectives in forming this kind of community-oriented choir.

Both conductors discussed the communal aspects of participating in a choir emphatically. They cited the positive musical and social aspects of the choir as being key to the creation and existence of the choir.

Shivon: I knew that singing together creates a field between people, a field of, you could say, connection and

\footnotetext{
${ }^{1}$ Contrary to what one might expect, reasons for joining the choir did not appear to have a direct impact on the results. Links between preexisting social connections and social outcomes within the choir were not consistent; the same can be said of desired intent upon joining the group and subsequent experience. Given this indication, I have chosen not to pursue the matter further in this paper. Further research may, however, be informative.
} 
fun and trust, an enjoyable field - what you could call community is created, and it gets people out of their shyness, it gets people out of their isolation - you really don't have to be talking about opinions, this and that... The voice is a great leveler, you know.

Denis: Just to form a really safe place where people could rediscover their voices, and develop a kind of community around that, which was supportive and musical and joyful.

The concepts of trust, connection, support, cooperation, and equality are evident in the above comments, and they emerge further in the response of participants. Both conductors noted that working together towards a common goal requires different levels of interpersonal engagement, which can in turn establish community:

Shivon: On the surface, we're all learning the song, we're learning the words of the song, we're learning the rhythm, we're learning the melody, we're learning the harmonies, all that - but the subtext of what's going on is, we're all practicing listening to ourselves and to each other at the same time. Which is a wonderful skill for building harmony, like, harmony in the community, harmony in the world.

Denis: There is an element, when you sing together, that is almost primal... It's the breathing, and the making sound, and the working towards a common goal, and a big part of it is...just listening and being really tuned in, and having your voice match the other people's voices, and being able to experience that. So you get the vibrations from them in your body and you pass your vibrations to them, and it all kind of becomes this soup, where the focus isn't on any individual, it's on what happens with all the individuals, because it's something no one person can do by themselves. 
The cooperative musical experience described above by Denis echoes Schütz's (1951) premise of the "mutual tuning-in relationship", and emphasizes the need for collective participation and equality. Also noted was the outreach and community service aspect of the choir, which situates the group within the greater social context:

Shivon: A community, to have longevity, has to have something outside of itself - it adds to the sense of purpose... It's a big part of community building.

This indicates that, like all avenues of communitas, the experience exists in balance with the structure of the enveloping society. Shivon gave further input on the social outcomes of singing:

Shivon: Somehow the singing together, well, it develops an atmosphere of trust. That feeling of 'I am because we are', that we are all connected...

The relationship between the "I" and the "We" (Buber; Schütz; Turner) was described as being a central aspect of the choral singing experience. Many of the points noted by the conductors also emerged in participant responses.

Participants' comments revealed that the feeling of communitas did indeed prove applicable to the choral singing experience. However, it became evident that communitas was facilitated through a variety of avenues, and, once present, was experienced in several ways. Most members cited a welcoming atmosphere as being present upon entering into either choir, and stressed the importance of the community aspect.

C: What I liked about the Gettin Higher Choir was...the spirit that Shivon and Denis bring to it - of, serious about what we're singing, but almost more for the building of community than for some kind of musical perfection. I feel it's one of the communities I'm part of in Victoria not just that you go there and go away again. 
T: This particular choir (the Victoria Good News Choir) is about community more than anything else, that's the highest priority... I think what's happened with this choir is the ones who stay are the ones who are seeking that community, want to be a part of it, contribute to it.

S: It's like its own little cosmos, its own community... (it's about) more than just arriving and warming up and singing, but also the element that Shivon and Denis cultivate - about community-building.

The environment and feeling of community, in most cases, seemed to be the first step towards generating a feeling of cohesion comparable to communitas. Given the nature of the choirs being studied, there was often a pre-existing recognition of the social function of the activity.

\section{Contributing factors}

\subsection{Common goals}

One repeatedly emerging catalyst for social bonding was the process of working together towards a common goal. In some cases, this took on specifically sonic attributes, but often it was the general collaborative process that participants cited as the source of cohesion. The interdependence of choir members in order to build a greater musical whole was recognized as a crucial component of the choral experience.

C: I think everybody singing together probably forms some form of community... I guess it must be something to do with intention, the shared intention to do something...The choir's kind of like that, we have a task, and our task is to learn these songs, and we learn them by heart. So we sing off book, and so you really have to make a commitment to do that... And so I guess it's everybody committing that amount of their time and energy, 
that draws you together, a shared enterprise or something like that.

S: It's individual in that you're working hard, and then you get to your goal, but it does have more of a sense of journey, or group creation - and then when you get there...finally...it's very satisfying.

The sensation of journeying described by S. suggests parallels with the state of liminality and the experience of communitas. The process of joining together as equals towards a common end is precisely that - a process - which can in some capacities be seen as akin to the ritual processes believed by Turner to facilitate the communitas phenomenon.

\subsection{Shared values and interests}

Often members expressed feelings of commonality derived from the mutual interests or values shared by other participants in the choral setting.

S: That sense of connection and purpose, whether it's working on a particular section and we get it, or that there is a common value system that I'm sharing with everyone there, so it feels like...potential for intensive emotional connection.

O: I meet a lot of people who have similar values - people that are into gardening, people who are into social justice, I meet people who care about the environment...A lot of us are in same demographic, we have similar ideas...you can always discuss things with people.

The perception of sharing values and social knowledge with a group of like-minded individuals was a strong component of the experience. Although members of the choir came from diverse backgrounds, participating in the choir placed them in a situation where they could set aside other differences in favour of what made them alike. 


\subsection{Accepting atmosphere}

Participants also mentioned the open, inviting, and safe environment of the choir as an important aspect of the positive social effect.

M: You go in there and there's this aura, there are all these people chatting, and smiling, 'Nice to see you, how was your week?' - people you haven't known very long.

G: I had some idea of the supportive nature of that choir, so that gets through some of my inherent resistance - being able to push my envelope, but being somewhat comfortable, somewhat safe.

T: It's very important that nobody feels bad in this choir... 'Welcome' comes out a lot, that word is the attitude.

This environment of safety and support appeared to be a direct facilitator of the experiences of equality and trust experienced by choir members. In this way, the structural components of the choir itself contributed to the potential for communitas among participants, presenting an interesting take on the structure/liminality dialectic discussed by Turner (1969).

\subsection{Community interaction}

Situating the activity within the greater community was, for some participants, an important aspect of the experience. Several noted that participating in the choir brought them into contact with other citizens in their city, with whom they would ordinarily have little contact. In some cases this referred to members of the choir, as below:

O: (There's) a lot of people you might not have met otherwise.

C: I guess...it's people that I would never encounter in my daily life... it makes me feel part of the community.

Both comments address the stretching and diversification of social ties, which can be important in reducing social isolation. In other 
cases, similar comments pertained to participants in the outreach settings, such as when choir members joined in singing with a weekly choir for disadvantaged citizens.

$\mathrm{T}$ : You change your judgment of people, because you're interacting with a population you wouldn't normally have interacted with...You expand your horizons by the opportunities that are part of this experience.

S: (The choir is) grounded locally and globally as well.

This ties back to the equalizing cause and effect of communitas, and the greater social repercussions and importance of the experience. Social status or hierarchies need no longer be relevant when singing, because - as noted in previous responses - all singers are equally required to contribute and to blend. Additionally, the experience brings together different parts of society, stitching together the larger whole.

\subsection{Social infrastructure}

Participants discussed a variety of social activities and setups connected with the choir, which facilitated further community building among participants.

I: We have a potluck at the beginning of each session, and I've gone to most of them - that's always fun. We made some friends, because we did some carpooling in our neighbourhood - made some very good friends.

T: We do social stuff too - there's potluck dinners...a bake sale, where we sell to each other and the money goes to the choir - and we've done people's birthdays...

O: I like the newsletter - it sort of keeps the group together.

From these responses, the contribution to group cohesion is evident. The infrastructure further emphasizes the unity of the choir, but also 
provides opportunities for social growth. One participant in particular stressed the social values of these activities.

C. The singing and the dancing and the eating are all important, but actually it's the being together that's important. Because we're social animals.

Some of these comments reveal increased lasting friendship ties. However, for the most part, they reveal the social microcosm that is the choir - a social venue or network that exists in and of itself, and in which people partake through participation.

\section{Outcomes}

The perceived outcomes of the choral singing experience are highly interconnected, but a few broad categories emerged.

\subsection{Connection}

Participants usually noted that they felt a connection to other choir members outside of the choral setting, even if it was simply an acknowledgment of mutual involvement.

I: Someone says they are part of the GHC and that's a little connection that we have, yeah.

S: (When out walking with elderly mum) Inevitably will see someone from choir, and it's because it's their community too, and so that's a very nice element. And we may or may not exchange words but we always smile or wave or something. So that is very validating, of one's 'humanness'...You feel like there's that shared experience, so I would feel...that there's a connection there, even though we don't know each other.

O: If we see each other we will talk - and there's some really interesting people.

M: The sopranos are over there and we're the altos - and often we don't know them, but when there's a potluck 
or we run into them in the street, "Oh, yes yes, you're a soprano!", (though) we've probably maybe not talked to them... You just feel a deep sense of connection with other people in the choir.

Participants indicate feeling that they have a bond that is outside their usual social circle, and that connects them with others who have shared in this community-building experience. Recognition of mutual involvement is an expected byproduct of a group activity, but these responses indicate that this can facilitate reduced social alienation through an extended network of acquaintances and involvement. The level of social connection differed among participants for some it was quite trivial, for others deeply meaningful, revealing that communitas, although widespread in some capacities, was not in fact a homogeneous experience.

\subsection{Caring}

The perception of being cared for by others in the choir emerged very strongly among some participant responses.

C: I like the community aspect, that everybody's really friendly and caring and supportive... I think that anytime you get together a group of people from diverse neighbourhoods and what have you, and give them a common goal and a common purpose, it draws people together, and anytime we draw together into community, then it's a more caring world that we're living in.

I. The choir community's been very powerful...(when our grandson was in hospital) the choir sang to us and for us...I would say that choir members care about each other in some way... I don't know a lot of names, but I know quite a few, so you know who you're singing to - it's great, we care about each other.

S. I suppose there is that sense of journeying, of all going together... and there's exposure, vulnerability, I think, 
that I experience and witness in varying degrees - so that closeness, and just admiration and caring that comes from that.

O. A nice group of people. Not in each other's face, but people care when you're there; it's a good feeling.

The above comments illustrate possibilities for social support through shared participation. Responses indicate a heightened interest and investment in fellow members of the choir, as well as the reciprocal personal experience of this phenomenon.

\subsection{Responsibility and equality}

The experience of contributing to a common cause appeared to emphasize the value that each participant brought to the whole. People described rising to the occasion in order to make the overall experience worthwhile for everyone involved, taking responsibility, but without expectation of individual recognition due to the communal nature of the experience.

I: There's something about doing that with all those other people, and making it flow together, and them doing another part, and we're doing another part, and that flows together... you lose your ego... (It's a) very ego-dissolving process.

$\mathrm{T}$ : The performance element, working up to putting it out there... Supporting each other - let's do this together, gotta make sure your buddy beside you gets it as well as you do - that empowerment of yourself and others is attractive, and it feels good to do that.

The feeling of equality in some cases extended to the directors, as choristers at times perceived them as creating an environment that facilitated that feature.

$\mathrm{J}$ : That competitive edge that you find sometimes in music isn't there...(the directors) model a level playing field 
like no choir conductors I've ever known about do, they're there with us...very much as equals...And the fact that we stand in a circle, I think says it all, for me.

Although the choir directors were in some ways the authority figures, their attitude also ensured that a perception of equal contribution remained present. This is yet another indicator of liminality and communitas among participants, as directors and choir members did not place themselves above or below other members, but instead focused on commonalities and accepted a position of equal stature.

\subsection{Trust}

Experiences of trust more often emerged through expressions of connection and community, than through explicit use of the definitive term. However, participants often cited the safe social environment as a means of establishing greater comfort with one's fellow singers.

C: I think there's a level of trust that, if you're there in community, everyone will be supportive.

The trust that is built by the choral experience is evident in the descriptions presented in this paper - of the caring attitude, the responsibility of contributing to the whole, and the feelings of shared connection with other choir members. The experience of communitas would seem to be closely tied to feelings of trust, in order for participants to fully engage with one another.

\section{Exceptions}

One participant in particular noted that she did not experience a strong social connection in her current choir. However, the participant's comments indicated that she had experienced feelings akin to communitas in previous choirs. It appeared that the ultimate decisive factor regarding collective bonding was the group's common goal in this case, the participant's musical goals differed from others in her current choir, which had not been the case previously. Therefore, 
one can gather that a shared sense of common purpose may need to be present before social cohesion can occur. This is consistent with Turner's (1969) criteria for liminality and, consequently, communitas, in which individuals join together with a shared desired outcome or experience.

Some participants emphasized that, although they recognized the strong social component of choir participation and considered the group a community, they did not consider themselves heavily involved or rely on it for their sole social fulfillment. This illustrates variation and fluctuating degrees to which people could feel part of a given social enterprise.

Others sought to develop or increase lasting friendships through the choir and joined it for this purpose, but found that this was not occurring. It may be that the social experience of coming together in song is dictated by its specific parameters, and requires the choir structure to be in place, without which social connections do not necessarily endure (a feature that would not be inconsistent with communitas as Turner [1969] describes it, as the effect derives primarily from the communal action itself). Here, perhaps, the plausible link between communitas-inducing experiences and greater social inclusion breaks down - for while one may be experiencing communitas in the moment, this does not necessarily translate to an increased support network for all participating parties.

\section{Discussion}

Over the course of the fieldwork, the community choir experience emerged through participants as a complex and nuanced social occurrence. Conversations with participants indicated that attaining social connection through singing can be a multifaceted process, with numerous variants and possibilities. In this instance, the activity was able to give rise to a range of positive social outcomes, yet these were in turn reached through several different avenues. The key factors of a common goal, shared values, a safe environment, community interaction, and social infrastructure were gateways through which 
the feelings of collective participation could be achieved. The outcomes included increased levels of trust, equality, connection, and mutual caring, which together were shown to form the basis for a common experience of communitas. Providing a categorical means of discussing the social experience of shared singing practices allows one to further build on the work of Kennedy (2009) and others in a practical fashion. Beyond generalized descriptions of social benefits, this approach brings greater depth and clarity to the topic, by identifying specific processes and requisite criteria for the feeling of communitas to emerge among participants. The experience was examined from the ground up, as it were, via the practice and process, rather than taking a top-down approach and only acknowledging the final product.

In this capacity, Turner's (1969) approach was helpful. The properties of ritual, liminality, and correlated social bonding, appropriately modified, revealed themselves to be a useful means of exploring and analyzing participant responses, providing a framework within which to situate and understand the dynamics of collective participation. The feelings of togetherness that can, at times, be derived from singing in a group are evocative of the characteristics of communitas and lend credence to Schütz's principle that making music together can facilitate social bonding.

Turner's system was nonetheless lacking in some capacities, not least because it failed to adequately account for the nuances and individual experiences of communitas for each participant, and instead focused primarily on the collective. The relatively rigid definitions of structure and of liminality, or anti-structure, in ritual contexts are also not feasible in this setting. Rather, the study results indicate that a feeling of communitas is, in some cases, enhanced by structured extra-curricular elements, therefore blurring the lines between the structured and the liminal. While Turner does acknowledge that one must exist in order for the other to occur, the choral setting seems to push even these boundaries, for its members move fluidly between the two states.

What this approach does accomplish, however, is to establish the 
choral social experience within a more universal social context. In knowing the specific processes that contribute to communitas and social cohesion in this setting, one can make a case for the utility of choirs as a social tool. As demonstrated in the literature review, many scholars have given indications of how such organizations can be socially viable. Their beneficial nature has been demonstrated among convicts, homeless persons, invalids, and the socially isolated, to name a few notable cases. However, these have mainly been developed on a case-by-case basis. With the approach of this paper, one can proceed to establish an operable set of ideal criteria for choirs with a social purpose. These choirs may be presented as requiring the following:

- A safe, non-threatening environment for participants

- Occasions for interaction with, and participation in, the greater community

- Extra-curricular opportunities for members

- A compelling, inclusive, shared mission and intent for the choir and its members (this may serve to links the elements of both common goals and values)

If these conditions are in place, one can make the reasonable assumption that the choir shares common traits with other liminal contexts and processes of social cohesion, and may thus be able to foster communitas, by way of the outcomes noted in this study.

To name a few possible examples of practical uses, social workers may concretely consider choirs as a viable means of socially supporting disadvantaged populations on an interpersonal level. Intercultural associations and community-building projects may recommend choirs as a way to feel less isolated, whether in a new location or in a socially difficult environment. Denis Donnelly and Shivon Robinsong each already offer singing workshops in business contexts, to facilitate greater relational skills and cohesion among participants (Donnelly, n.d; Robinsong, n.d.). For every traditional support group, might there not also be a singing group for those who wish to participate? Their functions differ somewhat, to be sure, but they may complement each other well. If the criteria is clear and the claims to 
communitas legitimate, the activity can move out of the recreational sphere and be considered as a valid means of bringing positive social change - or at least moments of meaningful interpersonal engagement - into the lives of many.

Still, more research remains. Responses were, in all probability, inspired by the community-oriented philosophy of the choir, placing limits on the data collected. Additionally, the choirs were highly localized and the sample size was small, therefore results can only truly represent the expressions of the participants. Further research is needed with other kinds of choirs, to evaluate whether the premises of equality and unity that inform the experience of communitas are present. The role of the conductors may be especially important if choirs are applied in social work contexts. The relationship between preexisting social networks and benefits derived from the choral context needs more investigation; additionally, it would be interesting to compare participants' social standpoints and priorities with their potential musical ones, and to identify divergence and overlap.

\section{Conclusion}

In the context of discussions surrounding social isolation and cohesion, the responses of participants offer an insightful grounded perspective on what the process of social bonding may entail. They bring to light the practices of engaging with one another through singing, by way of a common goal, shared values, a safe environment, community interaction, and social infrastructure, and they display the relation to the subsequent outcomes of trust, equality, connection, mutual caring, and ultimately communitas. These results offer the strong possibility that choral singing may effectively facilitate similar social developments in varied situations. From within the confines of this study, it is clear that singing together has the capacity to foster a sense of communitas and collective collaboration - we now stand poised to discover the many manifestations of this experience that still lie before us. 


\section{REFERENCES}

Bailey, B.A. \& Davidson, J.W. (2002). Adaptive characteristics of group singing: perceptions from members of a choir for homeless men. Musicae Scientiae, 6, 221-256.

Bailey, B.A. \& Davidson, J.W. (2003). Amateur group singing as a therapeutic instrument. Nordic fournal of Music Therapy, 12(1), 18-32. http://dx.doi.org/10.1080/08098130309478070

Bailey, B.A. \& Davidson, J.W. (2005). Effects of group singing and performance for marginalized and middle-class singers. Psychology of Music, 33(3), 269-303. http://dx.doi.org/10.1177/0305735605053734

Buber, M. (1970). I and thou: Ich und du. (W. A Kaufmann, Trans.). New York: Scribner. (Original work published 1923)

Cattan, M., Newell, C., Bond, J., \& White, M. (2003). Alleviating social isolation and loneliness among older people. The International fournal of Mental Health Promotion, 5(3), 20-30. $\begin{gathered}\text { http://dx.doi.org/10.1080/ } \\ 14623730.2003 .9721909\end{gathered}$

Cohen, G.D. (2006). Research on creativity and aging: the positive impact of the arts on health and illness. Generations, 30(1), 7-15.

Cohen, G.D., Perlstein, S., Chapline, J., Kelly, J., Firth, K.M., \& Simmens, S. (2006). The impact of professionally conducted cultural programs on the physical health, mental health, and social func-

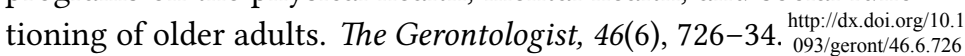

Creech, A., Hallam, S., McQueen, H., \& Varvarigou, M. (2013). The power of music in the lives of older adults. Research Studies in Music Education, 35(1), 87-102. http://dx.doi.org/10.1177/1321103x13478862

Dingle, G.A., Brander, C., Ballantyne, J.,\& Baker, F.A. (2012). 'To be heard': the social and mental health benefits of choir singing for disadvantaged adults. Psychology of Music, 41(4): 405-421. http:///xx.doi.org/10.117

Donnelly, Denis (n.d.). Workshops for the Business Community. Denis Donnelly. Retrieved from http://www.denisdonnelly.ca/singing business.html

Dunbar, R.I.M., Kaskatis, K., MacDonald, I., \& Barra, V. (2012). Performance of music elevates pain threshold and positive affect: Implications for the evolutionary function of music. Evolutionary Psychology: An International fournal of Evolutionary Approaches 
to Psychology and Behavior, 10(4): 688-702 http://dx.doi.org/10.1177 $/ 147470491201000403$

Durrant, C. (2005). Shaping identity through choral activity: Singers' and conductors' perceptions. Research Studies in Education, 24(1), 88-98. http://dx.doi.org/10.1177/1321103x050240010701

Eade, J. \& Sallnow, M. (Eds.). (1991). Contesting the Sacred: The Anthropology of Christian Pilgrimage. London: Routledge.

Eades, G. \& O'Connor, M. (2008). Sounds lively! choirs: Introducing singing into healthcare. The fournal of the Royal Society for the Promotion of Health, 128(2), 60-61. http://dx.doi.org/10.1177/1466424007087879

Fogg , L., \& Talmage, A. (2011). The CeleBRation choir: Establishing community group choral singing for people living with neurological conditions. Psychomusicology, 21 (1/2), 264-267. http://dx.doi.org/1

Gennep, Arnold van. (1909). The rites of passage. (Monika B. Vizedom and Gabrielle 1. Caffee, Trans.). London: Routledge and Kegan Paul. http://dx.doi.org/10.4324/9781315017594

Gick, M.L. (2011). Singing, Health And Well-Being: A Health Psychologist's Review. Psychomusicology, 21(1/2), 176-207. http:///dx.doi.org/1

Grape, C., Sandgren, M., Hansson, L.-O., Ericson, M., \& Theorell, T. (2002). Does singing promote well-being?: An empirical study of professional and amateur singers during a singing lesson. Integrative Physiological and Behavioral Science, 38(1), 65-74. ${ }_{1007 / \mathrm{htp} / \mathrm{do2} 2734261}$

Josephson, E., \& Josephson, M. (1962). Man alone: alienation in modern society. New York: Dell Pub. Co

Judd, M. \& Pooley, J.A. (2014). The psychological benefits of participating in group singing for members of the general public. Psychology of Music, 42(2), 269-283. http://dx.doi.org/10.1177/0305735612471237

Hortulanus, R.P., Machielse, A., \& Meeuwesen, L. (2006). Social isolation in modern society. London: Routledge. http://dx.doi.org/10.4324/9780203020142

Kennedy, M.C. (2009). The Gettin' Higher Choir: Exploring culture, teaching and learning in a community chorus. International fournal of Community Music, 2(2-3), 183-200. http://dx.doi.org/10.1386/ijcm.2.2-3.183_1

Lindenberger, U., Li, S.-C., Gruber, W., \& Müller, V. (2009). Brains swinging in concert: Cortical phase synchronization while playing guitar. BMC Neuroscience, 10(1): 22-34. http://dx.doi.org/10.1186/1471-2202-10-22 Marx, K., (1974). Economic and philosophic manuscripts of 1844: Se- 
lected works. (M. Milligan, Trans.). Moscow: Progress Publishers. (Original work published 1927)

Murchland, B. (1971). The age of alienation. New York: Random House.

Pappenheim, F. (2000). Alienation in American society. Monthly Review, 52(2), 36-53. (Originally published 1964). http:///dx.doi.org/10.1445

Robinsong, S. (n.d.). Everyone Can Sing! Shivon Robinsong. Retreived from http://shivonrobinsong.com

Schütz, A. (1951). Making Music Together: A Study in Social Relationship. Social Research, 18(1): 76-97. Retrieved from http://www.jstor org/stable/40969255

Silber, L. (2005). Bars behind bars: The impact of a women's prison http://dx.doi.org choir on social harmony. Music Education Research, 7(2), 251-71. ${ }_{800500169811}^{110.1080 / 1413}$

Teater, B., \& Baldwin, M. (2014). Singing for successful ageing: The perceived benefits of participating in The Golden Oldies CommunityArts Programme. British fournal of Social Work, 44(1), 81-99. ${ }_{1.1093 / \mathrm{h} b \mathrm{jww} / \mathrm{bcs} 095}$

Turino, T. (2008). Music as social life: The politics of participation. Chicago: University of Chicago Press.

Turner, E.L.B. (2012). Communitas: The anthropology of collective joy. New York: Palgrave Macmillan Ltd.

Turner, V.W. (1969). The ritual process: Structure and anti-structure. Vol. 1966. Chicago: Aldine Pub. Co.

Turner, V.W. (1986). The anthropology of performance. New York, N.Y: PAJ Publications.

Vickhoff, B, Malmgren, H., Aström, R., Nyberg, G., Ekström, S.-R., Engwall, M., Snygg, J., Nilsson, M., \& Jörnsten, R. (2013). Music structure determines heart rate variability of singers. Frontiers in Psychology, 334(4), 1-16. http://dx.doi.org/10.3389/fpsyg.2013.00334 